\title{
Model of optimal current feeding in zooplankton
}

\author{
Markus Pahlow*, A. E. Friederike Prowe \\ IFM-GEOMAR, Düsternbrooker Weg 20, 24105 Kiel, Germany
}

\begin{abstract}
Zooplankton feeding formulations in plankton models have exclusively focused on the relation between food concentration and ingestion, with respiration and excretion being treated separately, despite experimental evidence for strong links among these processes. We present an optimal current-feeding model linking ingestion, respiration, and assimilation efficiency to foraging activity. The Ivlev model is a special case of our optimal current-feeding model, which applies to static feeding behaviour. We validate our model with experimental data for copepods, ciliates, and dinoflagellates. Parameter estimates suggest that phylogenetic grouping is more important than predator size in determining feeding behaviour. Respiratory costs of foraging, e.g. for generating a feeding current, may be much larger than previously thought, are larger in smaller organisms, and might explain the independent development of feeding thresholds in different micro- and mesozooplankton groups. Both preferential feeding on, and lower feeding thresholds for, larger food particles are predicted to derive from greater capture efficiency owing to enhanced detectability of larger particles. The relation between feeding threshold and prey size appears to depend on feeding strategy but not on predator size, as a common relationship seems to apply for current feeders (ciliates and copepods) spanning a vast size range. Our model exhibits an inverse relationship between ingestion and assimilation efficiency, reducing the contribution of copepods to export of organic matter relative to remineralisation at low food concentrations. Export ratio variations previously thought to require strong shifts in community composition can be generated by changes in feeding behaviour predicted by our model.
\end{abstract}

KEY WORDS: Zooplankton · Optimal foraging · Current-feeding model Resale or republication not permitted without written consent of the publisher

\section{INTRODUCTION}

Marine zooplankton forms the first gateway in the processing of organic matter derived from primary production in the surface ocean. The fate of this organic matter is thus to a large part a function of 3 quantities which define zooplankton feeding behaviour and growth: (1) specific ingestion rate $I$ is the total food intake, (2) assimilation efficiency $E$ defines the assimilated and excreted fractions of the ingested material, and (3) respiration and exudation separate remineralisation from growth, i.e. accumulation of biomass available for utilisation by higher trophic levels. Net growth rate $g$ can be defined as the balance between assimilation $E I$ and respiration $R$ :

$$
g=E I-R
$$

where $R$ represents respiration of $\mathrm{CO}_{2}$ and exudation of nutrients (all symbols are summarised in Table 1). Sloppy feeding and risk of higher predation will not be considered in the present study. Excretion in the form of faecal pellets can be exported to the deep ocean and thereby contribute to the biological carbon pump. Consequently, the zooplankton formulation strongly affects the behaviour of plankton models both directly via its role in the food web and indirectly via its impact on vertical nutrient profiles (Steele \& Henderson 1992). Nevertheless, although many zooplankton models exist (Gentleman et al. 2003), they focus almost exclusively on ingestion and do not usually allow for dynamic adjustments in feeding behaviour (Paffenhöfer et al. 2007).

Behaviours effecting prey encounter can broadly be categorised into several foraging strategies. The sim- 
Table 1. Optimal current-feeding model variables and parameters

\begin{tabular}{|c|c|c|}
\hline Symbol & Standard units & Description \\
\hline$A_{\mathrm{f}}$ & $\mathrm{d}^{-1}$ & Specific foraging activity \\
\hline$A_{\mathrm{f}, \max }$ & $\mathrm{d}^{-1}$ & Maximum specific foraging activity \\
\hline$A_{\mathrm{t}}$ & $d^{-1}$ & Maximum total specific activity \\
\hline$\alpha$ & - & Prey handling coefficient \\
\hline$\beta$ & - & Digestion (assimilation) coefficient \\
\hline$C_{\mathrm{a}}$ & - & Cost of assimilation coefficient \\
\hline$C_{\mathrm{f}}, C_{\mathrm{f}}^{*}$ & - & Cost of foraging activity coefficient ${ }^{a}$ \\
\hline E & - & Assimilation efficiency \\
\hline$\widetilde{E}_{\mathrm{g}}$ & - & Modified gross growth efficiency ${ }^{b}$ \\
\hline$E_{\max }$ & - & Maximum assimilation efficiency \\
\hline$E_{\min }$ & - & Minimum assimilation efficiency \\
\hline$\varepsilon$ & - & Prey detectability coefficient \\
\hline$F_{0}$ & $\mathrm{~m}^{3} \mathrm{~d}^{-1}$ predator $^{-1}$ & Feeding-current strength \\
\hline$\varepsilon F$ & $\mathrm{~m}^{3} \mathrm{~g} \mathrm{C}^{-1} \mathrm{~d}^{-1}$ & Effective feeding-current strength \\
\hline$F$ & $\mathrm{~m}^{3} \mathrm{~g} \mathrm{C}^{-1} \mathrm{~d}^{-1}$ & Specific feeding-current strength \\
\hline$g$ & $\mathrm{~d}^{-1}$ & Net growth rate \\
\hline$g_{\max }$ & $\mathrm{d}^{-1}$ & Maximum net growth rate \\
\hline$h_{0}$ & d predator prey $^{-1}$ & Handling time \\
\hline$h$ & d $1-1$ & Specific handling time \\
\hline$I_{0}$ & prey predator ${ }^{-1} \mathrm{~d}^{-1}$ & Ingestion rate \\
\hline$I$ & $\mathrm{~d}^{-1}$ & Specific ingestion rate \\
\hline$I_{\max }$ & $\mathrm{d}^{-1}$ & Maximum specific ingestion rate \\
\hline$m_{\mathrm{p}}$ & g C prey $^{-1}$ & Prey size (biomass) \\
\hline$m_{\mathrm{z}}$ & g C predator $^{-1}$ & Predator size (biomass) \\
\hline$n_{\mathrm{p}}$ & prey $\mathrm{m}^{-3}$ & Prey abundance \\
\hline$P$ & $\mathrm{~g} \mathrm{C} \mathrm{m}^{-3}$ & Prey concentration \\
\hline$P_{\mathrm{g}}$ & $\mathrm{g} \mathrm{C} \mathrm{m}^{-3}$ & Growth threshold prey concentration \\
\hline$P_{\mathrm{m}}$ & $\mathrm{g} \mathrm{C} \mathrm{m}^{-3}$ & Prey concentration at peak clearance \\
\hline$P_{\text {th }}$ & $\mathrm{g} \mathrm{C} \mathrm{m}^{-3}$ & Feeding threshold prey concentration \\
\hline$\phi$ & $\mathrm{m}^{3} \mathrm{~g} \mathrm{C}^{-1}$ & Prey capture coefficient \\
\hline$\Pi$ & $\mathrm{g} \mathrm{C} \mathrm{m} \mathrm{m}^{-3}$ & Effective prey concentration \\
\hline$R_{\mathrm{M}}$ & $\mathrm{d}^{-1}$ & Specific maintenance respiration \\
\hline
\end{tabular}

pendages (Koehl \& Strickler 1981), which act to detect and capture prey organisms from the feeding current (Visser \& Stips 2002). Therefore, we refer to this feeding mode as current feeding.

Grazing functions commonly applied in plankton models include the Holling types, based on the disk equation, which in turn was derived for insect feeding (Holling 1959, 1973), and the Ivlev equation, derived for fish (Ivlev 1961). Their application to zooplankton was empirically motivated (Conover 1968, Fujii et al. 1986) and had no mechanistic basis. Aside from the inappropriateness of the term filter feeder to describe suspension feeding by copepods, this lack of a mechanistic foundation means that it is difficult to generalise these models and analyse disagreements between models and observations. For example, Parsons et al. (1967) noted the necessity to introduce a feeding threshold into the Ivlev equation in order to describe the behaviour of copepods. Vidal (1980a) and Kiørboe et al. (1982, 1985) introduced entirely new empirical formulations to describe their observations, which fit their data better but could 'not be interpreted in biological terms' (Kiørboe et al. 1982, p. 185).

Almost all existing zooplankton feeding models describe ingestion as a function of food concentration, without any inherent link to respiration or assimilation efficiency, despite many observations that these processes covary in a systematic manner (e.g. Landry et al. 1984, Kiørboe et al. 1985). Respiration can be consid-

plest possible behaviour is simply waiting for random prey encounters (ambush feeding), which is efficient for moving prey only (Gerritsen \& Strickler 1977). The most effective means of increasing prey encounters is cruise feeding, i.e. swimming in various patterns, but in addition to metabolic costs, this strategy also inevitably increases encounters with higher predators (Visser et al. 2009). A feeding current can enhance prey encounters as well, albeit somewhat less effectively, owing to its limited spatial extent. However, because the predator itself is not moving, this strategy does not suffer the increased risk of higher predation incurred by cruise feeding. Filter feeders direct their feeding currents through a filter, sieving out prey particles, which works most efficiently with very large filters (Gerritsen et al. 1988). Suspension-feeding copepods have often been considered filter feeders (e.g. Conover 1968, Frost 1972, Lehman 1976, Vidal 1980a), but one important yet still often ignored aspect of this feeding mode is that a copepod's feeding current does not pass through but actually around its feeding apered the sum of 3 components: (1) a constant maintenance respiration thought to sustain standard (resting) metabolism, (2) the cost of foraging, and (3) the metabolic cost of assimilation, termed specific dynamic action (Steele \& Mullin 1977). The increase of respiration with increasing growth rate is usually attributed mostly to specific dynamic action (Steele \& Mullin 1977, Kiørboe et al. 1985), whereas the cost of foraging has been suggested to give rise to feeding thresholds in order to save energy in the absence of food (Frost 1975). Zooplankton assimilation efficiency appears to decrease with increasing growth rate (Steele \& Mullin 1977, Kiørboe et al. 1985), yet it is usually treated as constant in plankton models (Lam \& Frost 1976, Steele 1998). The only existing feeding model utilising mechanistic relationships among ingestion, respiration, and assimilation efficiency is the optimal foraging description of filter feeding by Lehman (1976). However, this model has never been validated and, because it cannot be written in closed form, is not suitable for use in larger plankton models. 
Optimal foraging theory has been used previously to construct models of filter and cruise feeding (Lam \& Frost 1976, Lehman 1976, Gerritsen \& Strickler 1977), but these formulations were never validated or employed in the formulation of plankton models. Recent developments in optimal foraging theory of zooplankton have been geared mostly towards food and patch selectivity (Pyke 1984, Garcia et al. 2007). Visser et al. (2009) recently included a trade-off between prey encounters and risk of higher predation in their optimal foraging model. In the following we derive, largely from first principles, a zooplankton optimal currentfeeding (OCF) model based on the idea that zooplankton optimise their growth by balancing the costs and benefits of foraging and assimilation. Because we will assume the cost of foraging to comprise increased respiration and reduced assimilation capacity, this approach produces a model with inherent links among ingestion, respiration, and excretion, suitable for inclusion in larger plankton models.

\section{MODEL}

The formulation of net growth rate in Eq. (1) implies that assimilation comprises 2 steps: (1) capture and ingestion of prey, $I$, and (2) the subsequent assimilation as reflected in $E$. Both specific foraging activity $A_{\mathrm{f}}$, necessary for capturing and ingesting prey, as well as digestion and anabolic processes, needed for assimilation, require energy, which must be supplied by respiration $R$. Thus at least 2 trade-offs can be explored to construct an optimal feeding model: (1) a trade-off between foraging activity and assimilation efficiency, and (2) the balance between assimilation, as defined by foraging activity and assimilation efficiency, and respiration (Fig. 1). We derive both of these trade-offs for our OCF model on the basis of the following assumptions:

(1) Both feeding current and handling rate (inverse of handling time, $h$ ) result from foraging activity and can be described as simple linear functions of specific foraging activity $A_{\mathrm{f}}$.

(2) The difference between specific total and foraging activities (expressed as $A_{\mathrm{t}}-A_{\mathrm{f}}$ ) is available for digesting and assimilating ingested material.

(3) A fixed proportion $\left(C_{\mathrm{a}}\right)$ of assimilated food is respired during assimilation of predator biomass.

(4) Foraging activity incurs both direct costs in the form of additional respiration $\left(C_{\mathrm{f}} A_{\mathrm{f}}\right)$ and indirect costs due to the necessary allocation of potential total specific predator activity $A_{\mathrm{t}}$ to foraging.

(5) Foraging activity is regulated so as to maximise predator net growth rate $g$ under steady-state conditions.

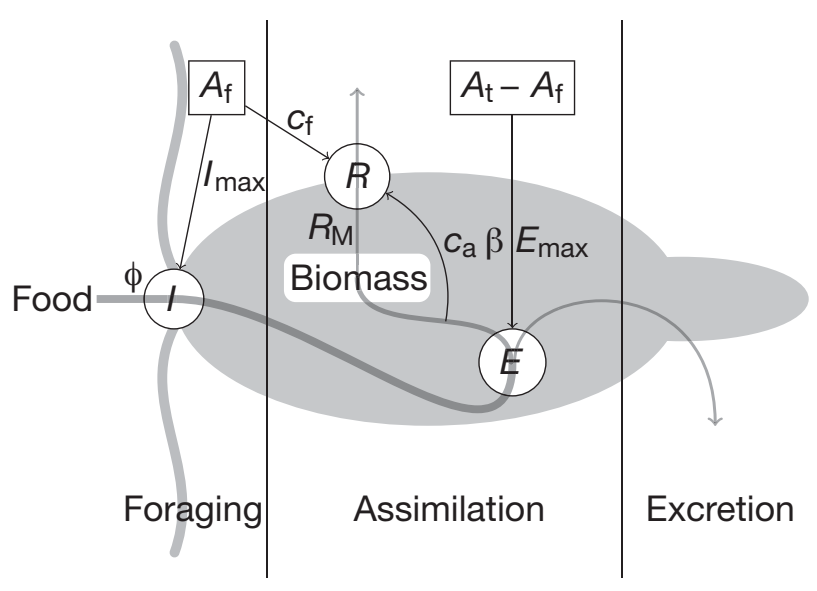

Fig. 1. Optimal current feeding of zooplankton balances opposing effects of specific foraging activity $A_{\mathrm{f}}$ on specific ingestion rate $I$ and assimilation efficiency $E$, and of ingestion and assimilation against respiration $R$. Foraging activity leads to capture and ingestion of food as determined by food concentration, maximum specific ingestion rate $I_{\max }$ and prey capture coefficient $\phi$, but also incurs respiration costs (cost of foraging coefficient, $C_{\mathrm{f}}$ ). Assimilation efficiency is a function of digestion (coefficient $\beta$ ) and governs the partitioning of ingested material into assimilated biomass and excretion. It is reduced by the allocation of the $A_{\mathrm{f}}$ part of potential total specific activity $A_{\mathrm{t}}$ to foraging activity and can reach values up to $E_{\max }$. The cost of assimilation coefficient $C_{\mathrm{a}}$ and specific maintenance energy requirements $R_{\mathrm{M}}$ also affect respiration

Respiration. Assumptions 3 and 4 define respiration as the sum of energy requirements for foraging, assimilation, and maintenance:

$$
R=C_{\mathrm{f}} A_{\mathrm{f}}+C_{\mathrm{a}} E I+R_{\mathrm{M}}
$$

where $C_{\mathrm{f}}$ is a cost coefficient relating foraging activity to respiration, $C_{\mathrm{a}} E I$ is specific dynamic action, and $R_{\mathrm{M}}$ is specific maintenance respiration.

Ingestion. Current feeding, i.e. ingestion via detecting and capturing prey from a feeding-current, can be considered analogous to light harvesting by the photosynthetic apparatus of a phytoplankton cell, where the prey stream (product of feeding current strength $F_{0}$ and prey abundance $n_{\mathrm{p}}$ ) corresponds to light intensity, the handling time needed for prey detection and capture $\left(h_{0}\right)$ corresponds to the reaction time of the photosynthetic reaction center, and the prey detectability coefficient $(\varepsilon)$ corresponds to the light absorption coefficient.

Detectability here is supposed to reflect factors such as size which could affect a predator's ability to detect and ingest prey, and thus is as much a property of the predator as of the prey. Baumert's (1996) derivation for photosynthesis as a function of light thus leads to the following interpretation of Ivlev's (1961) equation for current feeding:

$$
I_{0}=\frac{1}{h_{0}}\left(1-\mathrm{e}^{-\varepsilon F_{0} h_{0} n_{\mathrm{P}}}\right)
$$


where $I_{0}$ is ingestion rate as number of prey ingested by a predator per day and $n_{\mathrm{p}}$ prey abundance. Eq. (3) can be transformed in terms of biomass(carbon)-specific quantities by assuming that handling time varies proportionally with predator-prey size ratio and feeding-current strength scales with predator size:

$I=I_{0} \frac{m_{\mathrm{p}}}{m_{\mathrm{z}}}=\frac{1}{h}\left(1-\mathrm{e}^{-\varepsilon F h P}\right), h=h_{0} \frac{m_{\mathrm{z}}}{m_{\mathrm{p}}}, F=\frac{F_{0}}{m_{\mathrm{z}}}, P=n_{\mathrm{p}} m_{\mathrm{p}}(4)$

where $I$ is biomass-specific ingestion rate, $F$ is biomassspecific feeding-current strength, $h$ is biomass-specific handling time, $P$ is prey concentration, $m_{\mathrm{p}}$ is prey size, and $m_{z}$ is predator size. The assumptions in Eq. (4) may be rather pragmatic, but the above derivation shows that they are implicit in applying the Ivlev equation to current feeding in mass-specific units. The strength of a feeding current does not necessarily mean its velocity, but can also refer to the fraction of time in which the feeding current (with constant velocity) is active (Price \& Paffenhöfer 1986). Since both velocity and temporal fraction of activity of a feeding current are obviously linearly related to prey-encounter rate, any difference between these 2 mechanisms of varying feeding-current strength $F$ will only affect the value of the prey detectability coefficient $\varepsilon$ in Eq. (4).

According to Eq. (4) and Assumption 1, specific ingestion rate can be formulated in terms of specific foraging activity $A_{\mathrm{f}}$ :

$$
I=\alpha A_{\mathrm{f}}\left(1-\mathrm{e}^{-\phi P}\right), \quad \frac{1}{h}=\alpha A_{\mathrm{f}}, \quad \varepsilon F=\frac{\phi}{h}=\phi \alpha A_{\mathrm{f}}
$$

where $\alpha$ and $\phi$ are the prey handling and capture coefficients, respectively, relating foraging activity to feeding current, detectability, and prey handling, and $\varepsilon F$ is effective feeding-current strength. The coefficients $\alpha$ and $\phi$ are compound parameters comprising efficiency, size, and geometry of the detection and ingestion apparatus as well as prey size. It is convenient to define $\hat{I}$ as:

$$
\hat{I}=1-\mathrm{e}^{-\phi P}
$$

whence specific ingestion rate becomes

$$
I=\alpha A_{\mathrm{f}} \hat{I}
$$

Assimilation efficiency. Digestion is modelled as the exponential decay of ingested material in the gut (Lehman 1976), which depends on gut-passage time (assumed proportional to handling time $h$, and hence inverse of specific foraging activity, $1 / A_{\mathrm{f}}$ ) and decay rate (proportional to $A_{\mathrm{t}}-A_{\mathrm{f}}$, Assumption 2). Thus we describe the decay rate as $\beta\left(A_{\mathrm{t}} / A_{\mathrm{f}}-1\right)$, where $\beta$ is a coefficient of proportionality, relating activity to digestion, i.e. assimilation. A negative relation between decay rate and foraging activity could become manifest in a decrease in digestive enzymes with increasing food concentration, as reported by Hassett \& Landry
(1983). Assimilation efficiency can thus be written as a function of specific foraging activity $A_{\mathrm{f}}$ :

$$
E=E_{\max }\left[1-\mathrm{e}^{-\beta\left(\frac{A_{\mathrm{t}}}{A_{\mathrm{f}}}-1\right)}\right]
$$

We define $\beta$ here such that $\alpha \beta A_{\mathrm{t}}$ is the potential rate of assimilation. Eq. (8) follows from the assumption that handling time and gut-passage time are directly related to each other, i.e. the rate at which food passes through the gut adjusts to the speed at which food enters the gut.

Optimal foraging. Substituting Eqs. (2) and (5) to (8) into Eq. (1) yields:

$g=E I-R=\underbrace{E_{\max }\left[1-\mathrm{e}^{-\beta\left(\frac{A_{\mathrm{t}}}{A_{\mathrm{f}}}-1\right)}\right] \alpha A_{\mathrm{f}} \hat{I}\left(1-C_{\mathrm{a}}\right)}_{=E I\left(1-C_{\mathrm{a}}\right)}-C_{\mathrm{f}}^{*} \alpha A_{\mathrm{f}}-R_{\mathrm{M}}(9)$ where the effective cost of foraging coefficient,

$$
C_{\mathrm{f}}^{*}=\frac{C_{\mathrm{f}}}{\alpha}
$$

was introduced for notational convenience. Eq. (9) indicates that both above-mentioned trade-offs, between foraging and digestion, and between assimilation and respiration, are related to specific foraging activity. The behaviour of net assimilation $E I\left(1-C_{a}\right)$ and net growth rate $g$ in Eq. (9) as functions of foraging activity is illustrated in Fig. 2 for several levels of food concentration. Clearly, the optimal level of foraging is positive if and only if food concentration $P$ is above some threshold concentration $P_{\text {th }}$. For $P=P_{\text {th }}$, net assimilation $E I\left(1-C_{\mathrm{a}}\right)$ just recovers the energy expended for the cost of foraging, $C_{\mathrm{f}} A_{\mathrm{f}}$, at very low foraging activity (Fig. 2A), resulting in an initial slope of zero in $g$ as a function of $A_{\mathrm{f}}$ (Fig. 2B). Thus no net energy gain can be achieved by foraging when food concentration is at or below the feeding threshold, hence the maximum in $g$ occurs at $A_{\mathrm{f}}=0$ for $P \leq P_{\mathrm{th}}$. In this case, the slope of net growth rate $g$ as a function of $A_{\mathrm{f}}$ is always equal to 0 or less (Fig. 2B). It follows that solving for a zero derivative of $g$ with respect to specific foraging activity $A_{\mathrm{f}}$ (Assumption 5) will maximise net growth rate only for food concentrations above $P_{\mathrm{th}}$ :

$$
\frac{\mathrm{d} g}{\mathrm{~d} A_{\mathrm{f}}}=\alpha\left\{E_{\max } \hat{I}\left(1-C_{\mathrm{a}}\right)\left[1-\left(1+\beta \frac{A_{\mathrm{t}}}{A_{\mathrm{f}}}\right) \mathrm{e}^{-\beta\left(\frac{A_{\mathrm{t}}}{A_{\mathrm{f}}}-1\right)}\right]-C_{\mathrm{f}}^{*}\right\} \stackrel{!}{=}=0, A_{\mathrm{f}}>0
$$

$\Rightarrow \alpha A_{\mathrm{f}}= \begin{cases}\frac{\alpha \beta A_{\mathrm{t}}}{-1-W_{-1}\left\{-\left[1-\frac{C_{\mathrm{f}}^{*}}{E_{\max } \hat{I}\left(1-C_{\mathrm{a}}\right)}\right] \mathrm{e}^{-(1+\beta)}\right\}} & \text { if } P>P_{\mathrm{th}}, \\ 0 & \text { if } P \leq P_{\mathrm{th}},\end{cases}$

where $W_{-1}$ is the-1-branch of the Lambert- $W$ function, defined as the inverse function of $x \mathrm{e}^{x}: W\left(x \mathrm{e}^{x}\right)=x$. A simple and accurate closed-form approximation for $W_{-1}$ is given in Barry et al. (2000). Eq. (12) describes 


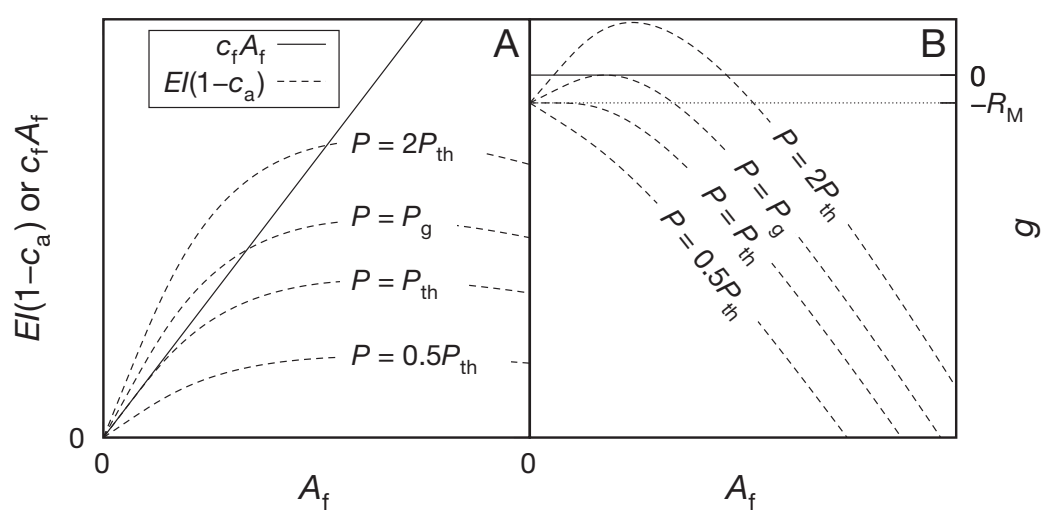

Fig. 2. Model behaviour. (A) Net assimilation and cost of foraging, $E I\left(1-C_{\mathrm{a}}\right)$ and $C_{\mathrm{f}} A_{\mathrm{f}}$, and (B) net growth rate, $g$, as functions of foraging activity $A_{\mathrm{f}}$ for different food concentrations $P$ relative to the feeding threshold $P_{\text {th }} . P_{\mathrm{g}}$ is the food concentration required for assimilation to cover maintenance energy requirements (growth threshold) and $R_{\mathrm{M}}$ is maintenance respiration
Thus, model behaviour is specified by the 7 parameters $\beta, C_{\mathrm{a}}, C_{\mathrm{f}}^{*}, E_{\max }, I_{\max }, \phi$, and $R_{\mathrm{M}}$ (Fig. 3). Maximum assimilation efficiency $E_{\max }$, prey capture coefficient $\phi$, and effective cost of foraging coefficient $C_{\mathrm{f}}^{*}$ determine the initial increase in net growth rate beyond the feeding threshold. Cost of assimilation coefficient $C_{\mathrm{a}}, C_{\mathrm{f}}^{*}$, and maximum specific ingestion rate $I_{\max }$ set the maximum growth rate (Fig. 3A). The initial rise in respiration with food concentration is mostly a function of $C_{\mathrm{f}}^{*}$ and $\phi$, whereas $C_{\mathrm{a}}$ and $I_{\max }$ exert strong control on maximum respiration (Fig. 3B). The feeding threshold increases with $C_{\mathrm{a}}$ and $C_{\mathrm{f}}^{*}$ and decreases with increasing $E_{\max }$ and $\phi . C_{\mathrm{f}}^{*}$ and $\phi$ are the main determinants of the effective optimal regulation of specific foraging activity, balancing specific ingestion rate $I$, assimilation efficiency $E$, and respiration $R$ which results in the maximal net growth rate given external (food concentration $P$ ) and internal (trade-offs among $I, E$, and $R$ ) limitations.

Feeding threshold. The threshold concentration $P_{\text {th }}$ required for feeding can be obtained from the condition that the initial slope of $g$ as a function of $A_{\mathrm{f}}$ must be greater than zero, which is equivalent to the requirement that the limit of Eq. (11) as $A_{\mathrm{f}} \rightarrow 0$ is positive:

$$
\begin{gathered}
\lim _{A_{\mathrm{f}} \rightarrow 0} \frac{\mathrm{d} g}{\mathrm{~d} A_{\mathrm{f}}}>0 \Leftrightarrow C_{\mathrm{f}}^{*}<E_{\max }\left(1-C_{\mathrm{a}}\right)\left(1-\mathrm{e}^{-\phi P}\right) \\
\Leftrightarrow P>\frac{1}{\phi} \ln \frac{1}{1-\frac{C_{\mathrm{f}}^{*}}{\mathrm{E}_{\max }\left(1-C_{\mathrm{a}}\right)}} \equiv P_{\mathrm{th}}
\end{gathered}
$$

Thus the feeding threshold $P_{\text {th }}$ is independent of the digestion coefficient $\beta$ and specific maintenance respiration $R_{\mathrm{M}}$. Digestion cannot interfere with the feeding threshold because it sets in only at food concentrations higher than the feeding threshold, and $R_{\mathrm{M}}$ only affects the threshold for positive net growth but not the feeding threshold. A food concentration exceeding $P_{\mathrm{g}}$ which is substantially higher than $P_{\text {th }}$ is needed to achieve positive net growth (Fig. 2), as maintenance energy requirements have to be covered in addition to the cost of foraging.

Model parameters. Total predator activity $A_{\mathrm{t}}$ can be specified as a function of the readily measured maximum specific rate of ingestion $I_{\max }$, which is related to maximum specific foraging activity $A_{\mathrm{f} \text {, max }}$ via $I_{\max }=$ $\alpha A_{\mathrm{f}, \max }$ at saturating food concentrations ( $\hat{I}=1$, Eq. 7$)$. Substituting $\alpha A_{\mathrm{f}}=I_{\max }$ and $\hat{I}=1$ in Eq. (12) and solving for $\alpha A_{t}$ gives:

$$
\alpha A_{\mathrm{t}}=\frac{I_{\max }}{\beta}\left\{-1-\mathrm{W}_{-1}\left[-\left(1-\frac{C_{\mathrm{f}}^{*}}{E_{\max }\left(1-C_{\mathrm{a}}\right)}\right) \mathrm{e}^{-(1+\beta)}\right]\right\}
$$
strength of the feeding current $\varepsilon F$ (Fig. 3C). Whereas foraging activity, and hence also the strength of the feeding current, monotonically increases with food concentration, clearance declines as food concentration increases beyond a certain food concentration $P_{\mathrm{m}}$ (Fig. 3C), as ingestion saturates towards its inherent maximum (Fig. 3A). When the cost of foraging is negligible $\left(C_{\mathrm{f}}^{*}=0\right.$ in Fig. $3 \mathrm{C}$ ), then $P_{\text {th }}=0$ and $E$ and $A_{\mathrm{f}}$ become independent of food concentration, such that $\varepsilon F$ is constant and optimal current feeding reduces to a simple Ivlev model (Eq. 5 with constant maximum specific rate of ingestion $\alpha A_{\mathrm{f}}$ ), which thus describes static feeding behaviour with constant specific foraging activity. $C_{\mathrm{a}}$ also exerts some influence on the initial decline of assimilation efficiency, which is otherwise mostly controlled by the digestion coefficient $\beta$ and $E_{\max }$ (Fig. 3D).

Temperature. Observations indicate that the minimum food concentration required for positive net growth $P_{\mathrm{g}}$ increases with temperature (Vidal 1980a), but the feeding threshold food concentration $P_{\text {th }}$ and the food concentration at peak clearance $P_{\mathrm{m}}$ do not (Wlodarczyk et al. 1992). Since $I$ and $P_{\text {th }}$ are non-linear functions of $\beta, C_{\mathrm{a}}, C_{\mathrm{f}}^{*}, E_{\max }$ and $\phi$ (Eqs. $\left.5 \& 14\right)$, the simplest assumption in accordance with temperatureindependent $P_{\mathrm{th}}$ and $P_{\mathrm{m}}$ is that none of these 5 parameters depend on temperature. It follows from this assumption that only 2 model parameters, $I_{\max }$ and $R_{\mathrm{M}}$, are temperature dependent, as neither $P_{\text {th }}$ nor $I$ depend on $R_{\mathrm{M}}$ and $I$ is linear in $I_{\max }$ (Eqs. 7 and 12).

Multiple food sources. The OCF model could be extended to multiple food species in at least 2 ways, depending on whether the predators are supposed to be specialists or omnivores. A specialist community could be represented by adding individual rates of ingestion, respiration, and excretion for all species. No modification of the OCF equations is necessary in this case. Supposing that several kinds of food of an omni- 


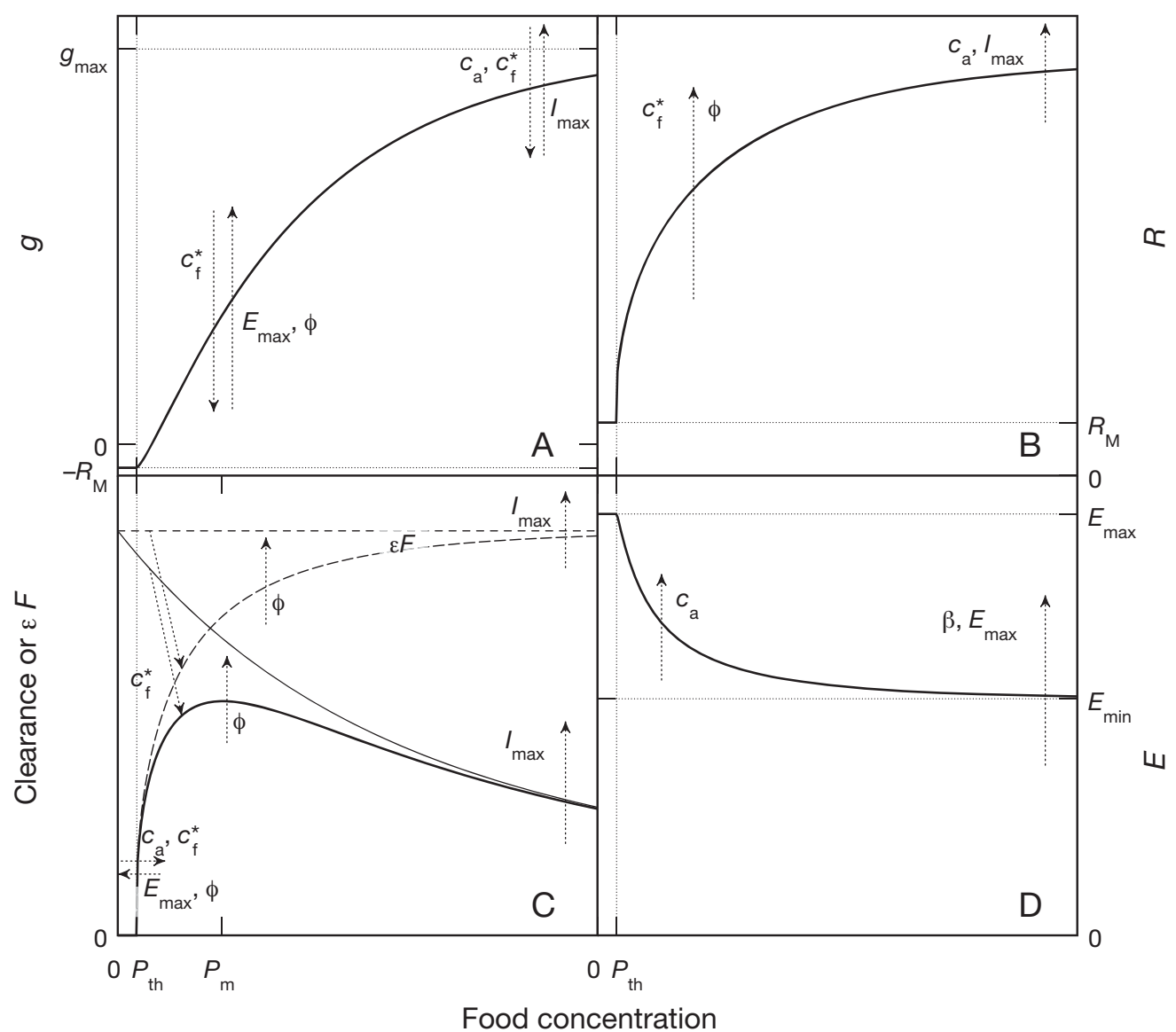

Fig. 3. Major effects of parameter variations on optimal current-feeding model behaviour as a function of food concentration. (A) net growth rate $(g) ;(B)$ respiration $(R) ;(C)$ clearance $(=I / P$; solid lines) and effective strength of feeding current $(\varepsilon F$, dashed lines); and (D) assimilation efficiency $(E)$. Arrows indicate effects of increasing parameter values. Thin lines in $(C)$ indicate model behaviour for $C_{\mathrm{f}}^{*}=0$. Increasing $E_{\max }$ and $\phi$ reduces the feeding threshold $P_{\mathrm{th}}$. Effects of $E_{\max }$ and $R_{\mathrm{M}}$ are indicated on the $y$-axes in (A), (B), and (D). $g_{\max }$ : maximum net growth rate; $E_{\min }$ : minimum assimilation efficiency; $P_{\mathrm{m}}$ : food concentration at peak clearance

vorous predator differ only in $\phi$, we modify Eqs. (6) and (14) to include all food species $P_{\mathrm{i}}$ and then divide specific ingestion rate proportionally among all the $P_{\mathrm{i}}$ :

$$
\hat{I}=1-\mathrm{e}^{-\Pi}, \Pi>\ln \frac{1}{1-\frac{C_{\mathrm{f}}^{*}}{\mathrm{E}_{\max }\left(1-C_{\mathrm{a}}\right)}}, \Pi=\sum_{i} \phi_{i} P_{i}, I_{i}=\frac{\phi_{i} P_{i}}{\Pi} I
$$

where $\Pi$ is the effective food concentration (Ambler 1986). Such a formulation is supported by observations that late-stage and adult Paracalanus responded identically to mixed and mono-algal food with the same effective food concentration (Paffenhöfer 1984, Ambler 1986). Omnivorous feeding should not be used to represent a community of specialists in this conceptual model, because Eq. (16) would underestimate both feeding thresholds and assimilation efficiencies. Application of Eq. (16) would also fail in cases where the predator switches feeding behaviour when eating different kinds of prey, e.g. current feeding for phytoplankton and ambush feeding for ciliates (Kiørboe et al. 1996).

\section{VALIDATION}

Model behaviour is illustrated and compared with observations from laboratory studies for copepods, ciliates, and dinoflagellates in Figs. 4 to 7 . We tuned the OCF model parameters by hand so as to obtain the best possible agreement with the observations, as assessed by visual inspection.

\section{Copepods}

Kiørboe et al. (1985) presented a budget of feeding, respiration, excretion, and growth for the copepod Acartia tonsa (Fig. 4). Although A. tonsa is an ambush feeder when preying on ciliates, this species switches to suspension feeding and generates a feeding current when feeding on phytoplankton (Jonsson \& Tiselius 1990, Kiørboe et al. 1996). The specific rate of egg production was used as a proxy for net growth rate $g$ 


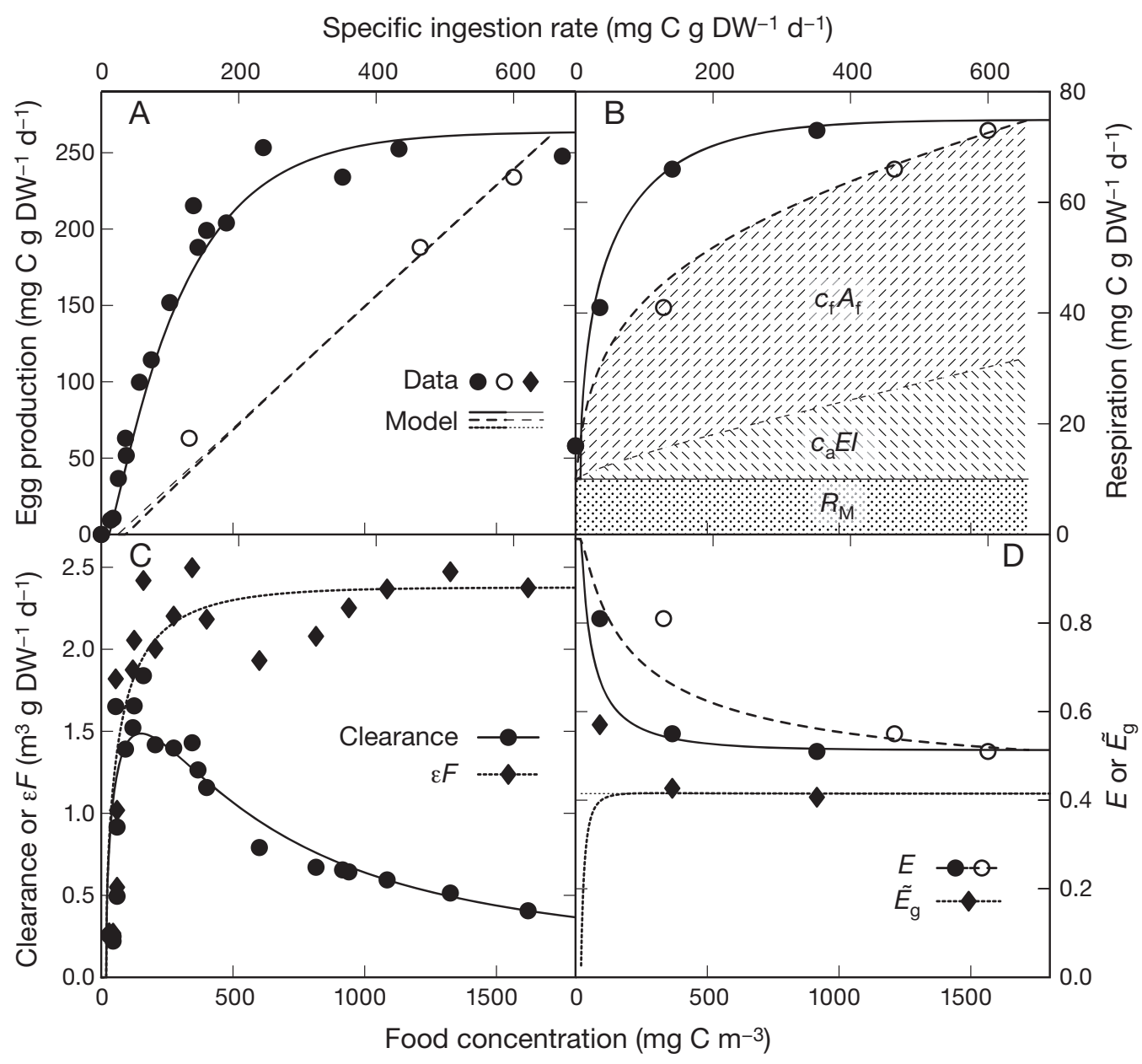

Fig. 4. Validation of the optimal current-feeding model with data of Acartia tonsa feeding on Rhodomonas baltica. Closed symbols and solid and dotted lines indicate relationships with food concentration (bottom axes), open symbols and dashed lines with specific ingestion rate (top axes). Thin lines in (A) and (D) are for the linear approximation of the relationship between egg production $(g)$ and specific ingestion rate. $\varepsilon F$ in $(C)$ is effective feeding-current strength. Shaded areas in (B) outline the contributions of the costs of foraging $\left(C_{\mathrm{f}} A_{\mathrm{f}}\right)$, specific dynamic action $\left(C_{\mathrm{a}} E I\right)$, and maintenance $\left(R_{\mathrm{M}}\right)$ to total respiration in relation to specific ingestion rate. $\widetilde{E}_{\mathrm{g}}$ is a modified gross growth efficiency (see Eq. 18 for details), $E$ is assimilation efficiency. DW: copepod dry weight. Data are from Kiørboe et al. (1985). Parameters are detailed in Table 2

(Fig. 4A), and assimilation efficiency E (Fig. 4D) was estimated assuming that specific ingestion rate is the sum of egg production, respiration, and excretion. Both egg production and respiration appear to be approximately linearly related to specific ingestion rate, except that respiration is reduced at zero ingestion, which is well reproduced by the model (Fig. 4A,B, open symbols and dashed lines). Linear relationships between ingestion and growth are frequently observed across a wide range of zooplankton organisms, ranging from protozoa to copepods (e.g. Kiørboe et al. 1985, Hansen 1992).

According to our model, the effective strength of the feeding current ( $\varepsilon F=\phi \alpha A_{\mathrm{f}}$, see Eq. 5) can be computed from specific ingestion rate as:

$$
\varepsilon F=\frac{\phi I}{1-\mathrm{e}^{-\phi P}}
$$

Figs. 3C \& 4C show that feeding current and specific foraging activity $A_{\mathrm{f}}$ increase monotonically with prey concentration, whereas clearance $(=I / P$, Fig. $4 \mathrm{C})$ exhibits a maximum at about $150 \mathrm{mg} \mathrm{C} \mathrm{m}^{-3}$ and then decreases with increasing food concentration. Clearance most clearly reveals the feeding threshold, below which clearance must be zero. Without a feeding threshold, clearance would approach its maximum toward a food concentration of zero (Fig. 3C, thin solid line). The predicted threshold for growth $(37.4 \mathrm{mg} \mathrm{C}$ $\mathrm{m}^{-3}$, Fig. 4A, thick solid line) is somewhat higher than the feeding threshold (20.2 $\mathrm{mg} \mathrm{C} \mathrm{m}^{-3}$; Table 2, Fig. 4C) due to maintenance respiration. Increasing foraging activity and specific ingestion rate with food concentration are accompanied by decreasing assimilation efficiency (Fig. 4D). Declining assimilation efficiency 
Table 2. Parameter settings of the optimal current-feeding model and empirically derived predator size, feeding thresholds, and maximum growth rates

\begin{tabular}{|c|c|c|c|c|c|c|c|c|c|c|}
\hline Taxon & $\beta$ & $C_{\mathrm{a}}$ & $C_{\mathrm{f}}^{*}$ & $E_{\max }$ & $\begin{array}{l}I_{\max } \\
\left(\mathrm{d}^{-1}\right)\end{array}$ & $\begin{array}{c}\phi \\
\left(\mathrm{m}^{3} \mathrm{~g} \mathrm{C}^{-1}\right)\end{array}$ & $\begin{array}{c}R_{\mathrm{M}} \\
\left(\mathrm{d}^{-1}\right)\end{array}$ & $\begin{array}{c}\text { Size } \\
\left(\mu \mathrm{g} \mathrm{C} \text { predator }^{-1}\right)\end{array}$ & $\begin{array}{c}P_{\mathrm{th}} \\
\left(\mathrm{mg} \mathrm{C} \mathrm{m}^{-3}\right)\end{array}$ & $\begin{array}{l}g_{\max } \\
\left(\mathrm{d}^{-1}\right)\end{array}$ \\
\hline \multicolumn{11}{|l|}{ Copepods } \\
\hline Acartia tonsa & 0.2 & 0.065 & 0.065 & 0.99 & $1.65^{\mathrm{a}}$ & 3.6 & 0.025 & $2.96^{\mathrm{c}}$ & 20.2 & $0.66^{\mathrm{a}}$ \\
\hline Calanus pacificus & 0.2 & 0.065 & 0.065 & 0.99 & 0.49 & $4.5-14.4^{\mathrm{b}}$ & - & $68^{\mathrm{d}}$ & $5.1-16.2^{\mathrm{b}}$ & - \\
\hline \multicolumn{11}{|l|}{ Ciliates } \\
\hline Strobilidium spiralis & 0.2 & 0.3 & 0.3 & 0.99 & 5 & 20 & 0.15 & $0.013^{\mathrm{e}}$ & 28.4 & 1.11 \\
\hline Strombidium sp. & 0.2 & 0.3 & 0.3 & 0.99 & 2.5 & 20 & 0.05 & $0.0054^{\mathrm{e}}$ & 28.4 & 0.58 \\
\hline Lohmanniella oviformis & 0.2 & 0.35 & 0.3 & 0.99 & 3.4 & 20 & 0.3 & $0.00072^{\mathrm{e}}$ & 31.3 & 0.46 \\
\hline $\begin{array}{l}\text { Dinoflagellate } \\
\text { Gymnodinium sp. }\end{array}$ & 0.2 & 0.33 & 0.25 & 0.99 & 2.9 & 220 & 0.05 & $180-360 \times 10^{-6 \mathrm{f}}$ & 2.15 & 0.7 \\
\hline
\end{tabular}

with increasing food concentration was also reported by Landry et al. (1984).

The slope of the approximately linear relationship between growth and ingestion can be interpreted as a modified gross growth efficiency $\left(\tilde{E}_{g}\right)$ as defined by Hansen (1992):

$$
\tilde{E}_{\mathrm{g}}=\frac{g+R_{\mathrm{M}}}{I} \approx \frac{g_{\max }+R_{\mathrm{M}}}{I_{\max }}=E_{\min }\left(1-C_{\mathrm{a}}\right)-C_{\mathrm{f}}^{*}
$$

where $g_{\max }$ and $I_{\max }$ are maximum net growth rate and specific ingestion rate, respectively, and $E_{\min }$ is the minimum assimilation efficiency (for $I=I_{\max }=A_{\mathrm{f}, \max }$ ):

$$
\begin{gathered}
g_{\text {max }}=E_{\min } I_{\text {max }}\left(1-C_{\mathrm{a}}\right)-C_{\mathrm{f}}^{*} I_{\max }-R_{\mathrm{M}} \\
E_{\min }=E_{\max }\left[1-\mathrm{e}^{-\beta\left(\frac{\alpha A_{\mathrm{t}}}{\alpha A_{\mathrm{f}, \max }}-1\right)}\right]
\end{gathered}
$$

$\widetilde{E}_{\mathrm{g}}$ is mostly constant except at the lowest prey concentrations in Fig. 4D, where the model diverges from the observations. However, the regression of egg production on ingestion presented by Kiørboe et al. (1985) has a positive $y$-axis intercept, indicating that the copepods were still producing some eggs after ingestion ceased, which the model cannot reproduce due to the steady-state assumption (Assumption 5). This phenomenon also implies that Kiørboe et al. (1985) might have overestimated assimilation efficiencies by assuming constant copepod weight in the course of a feeding experiment, and hence explains at least part of the discrepancy between modelled and observed assimilation efficiency at the lowest food concentration in Fig. 4D.

Fig. 5 shows the model fit to observations on the copepod Calanus pacificus feeding on diatoms of different cell size. Since only ingestion was reported by
Frost (1972), the model could not be fully constrained by this data set, hence we used values obtained for Acartia tonsa for $\beta, C_{\mathrm{a}}, C_{\mathrm{f}}^{*}$, and $E_{\max }$. When fitting the model to these data, the differences among the feeding responses to the different food algae could be described by varying only the prey capture coefficient $\phi$. Expressing $\phi$ as a simple saturating function of cell diameter (Table 2) produced a reasonable agreement between model and observations, which implies a straightforward interpretation of $\phi$ as the efficiency of detecting and capturing food from the feeding current: food particles too small to be detected by the feeding appendages also cannot be captured, setting a lower size limit to particles which can be utilised (Frost 1972); larger particles are more easily detected and hence captured, leading to increasing $\phi$ with increasing particle size. While it is clear that there must also be an upper size limit above which food particles become difficult and eventually impossible to handle (implying decreasing $\phi$ with increasing size), food algae of this size were not used in the study by Frost (1972). The prey-size dependence of $\phi$ generates an inverse relationship between prey size and feeding threshold, which appears to hold across all current feeders considered in the present study (Fig. 5, inset).

\section{Ciliates}

Copepod and ciliate feeding behaviour exhibit several common features, such as generating a feeding current and releasing faecal aggregates (Jørgensen 1983, Stoecker 1984). The OCF model is compared to observations of 3 ciliate species feeding on small phyto- 


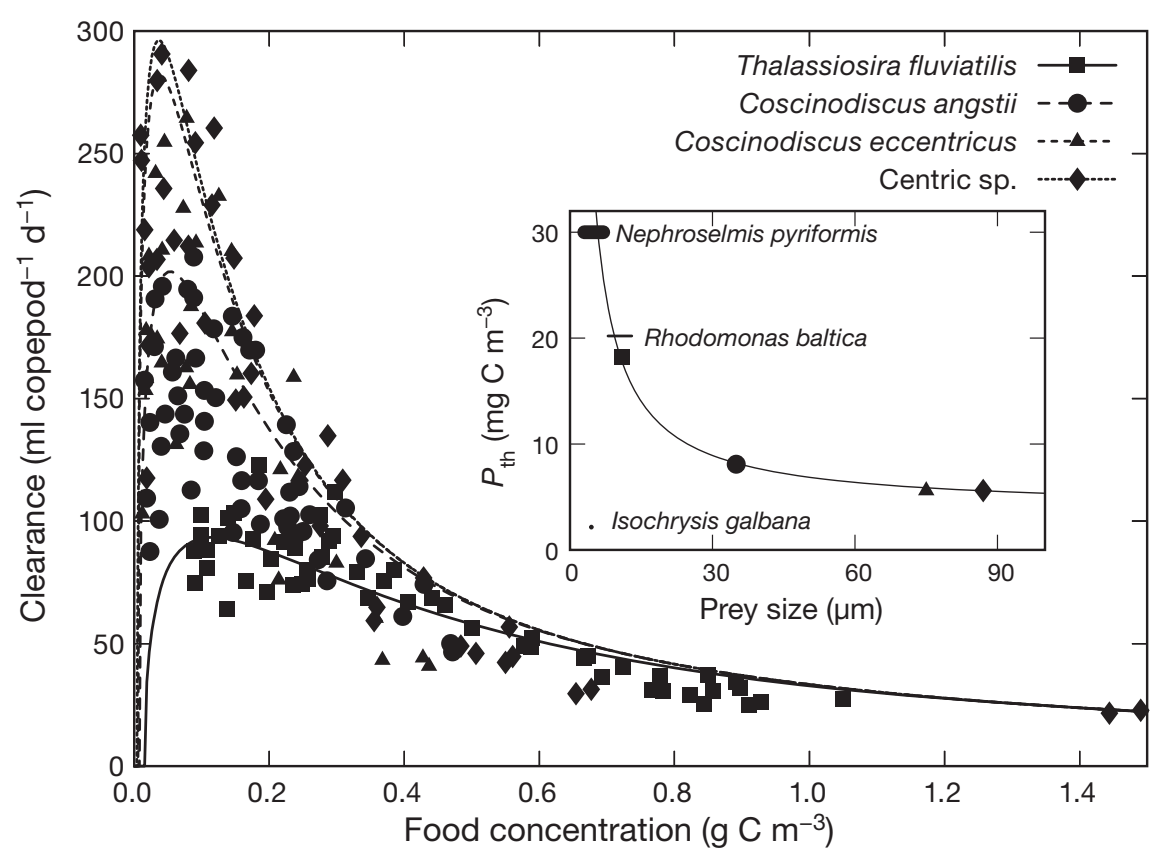

Fig. 5. Validation of the optimal current-feeding model with data of Calanus pacificus feeding on centric diatoms. The model was first fitted to the largest prey (Centric sp., dotted line) and then $\phi$ was reduced as a saturating function of prey size (see Table 2) to obtain fits for the smaller diatom species (solid and dashed lines). Data from Frost (1972). Parameters are detailed in Table 2. Inset: relationship between feeding threshold $P_{\text {th }}$ and prey size resulting from the prey-size dependence of $\phi$. Symbols correspond to the legend in the outer figure. Thickness of horizontal lines indicates range of feeding thresholds for Acartia tonsa and ciliates in Table 2, and length of horizontal lines indicates minimum and maximum cell dimensions (e.g. width and length) of Rhodomonas baltica and Nephroselmis pyriformis used as prey by Kiørboe et al. (1985) and Gismervik (2005), respectively. Dot indicates size of Isochrysis galbana (Strom 1991) and corresponding feeding threshold for Gymnodinium sp. from Table 2. Dimensions of N. pyriformis are from the Swedish Meteorological and Hydrological Institute (www.smhi.se)

plankton in Fig. 6. All 3 species seem to have similar feeding thresholds and clearance peaks at similar food concentrations. These data also do not fully constrain the model, as no assimilation efficiencies were reported, such that $\beta$ and $E_{\max }$ were set to their estimates for Acartia tonsa (Table 2). Nevertheless, it appears noteworthy that all 3 species, feeding on the same or very similar prey using a feeding current, could be fitted with the same $C_{\mathrm{f}}^{*}$ and $\phi$, which are the parameters characterising the feeding current (Fig. 3C), and which are responsible for the similarities in feeding thresholds and food concentrations at peak clearance. Strong differences in parameter estimates were found only in maximum specific rate of ingestion $I_{\max }$ and specific maintenance respiration $R_{\mathrm{M}}$ (Table 2), reflecting the differences among net growth rates at zero and saturating food concentrations (see Fig. 3A).

\section{Dinoflagellates}

The feeding behaviour of dinoflagellates is quite different from that of copepods and ciliates in that dinoflagellates do not generate feeding currents but acquire food by means of cruise feeding. Since it does not matter in terms of encounter rate whether a predator moves through water or water moves past a predator, this mode of foraging should follow the same functional relationship with food concentration as current feeding (Eqs. 3 to 5). Indeed, flagellate feeding behaviour as observed by Strom (1991) appears to concur qualitatively with that of copepods and ciliates shown above (Fig. 7). As with Fig. 6, $\beta$ and $E_{\max }$ could not be constrained. The modelled relationship between net growth rate and specific ingestion rate deviates more strongly from a straight line in Fig. 7A than in Fig. 4A because of the larger costs of assimilation and foraging estimated for the dinoflagellate (Table 2). However, in the region where net growth is positive, i.e. for $I \gtrsim 0.6 \mathrm{~d}^{-1}$, the predicted relationship is again an almost perfectly straight line. Although the data are less clear in this respect than those in Figs. 4 to 6, clearance peaks well above the lowest food concentrations for both days of the experiment shown in Fig. 7B, which indicates the presence of a feeding threshold. 


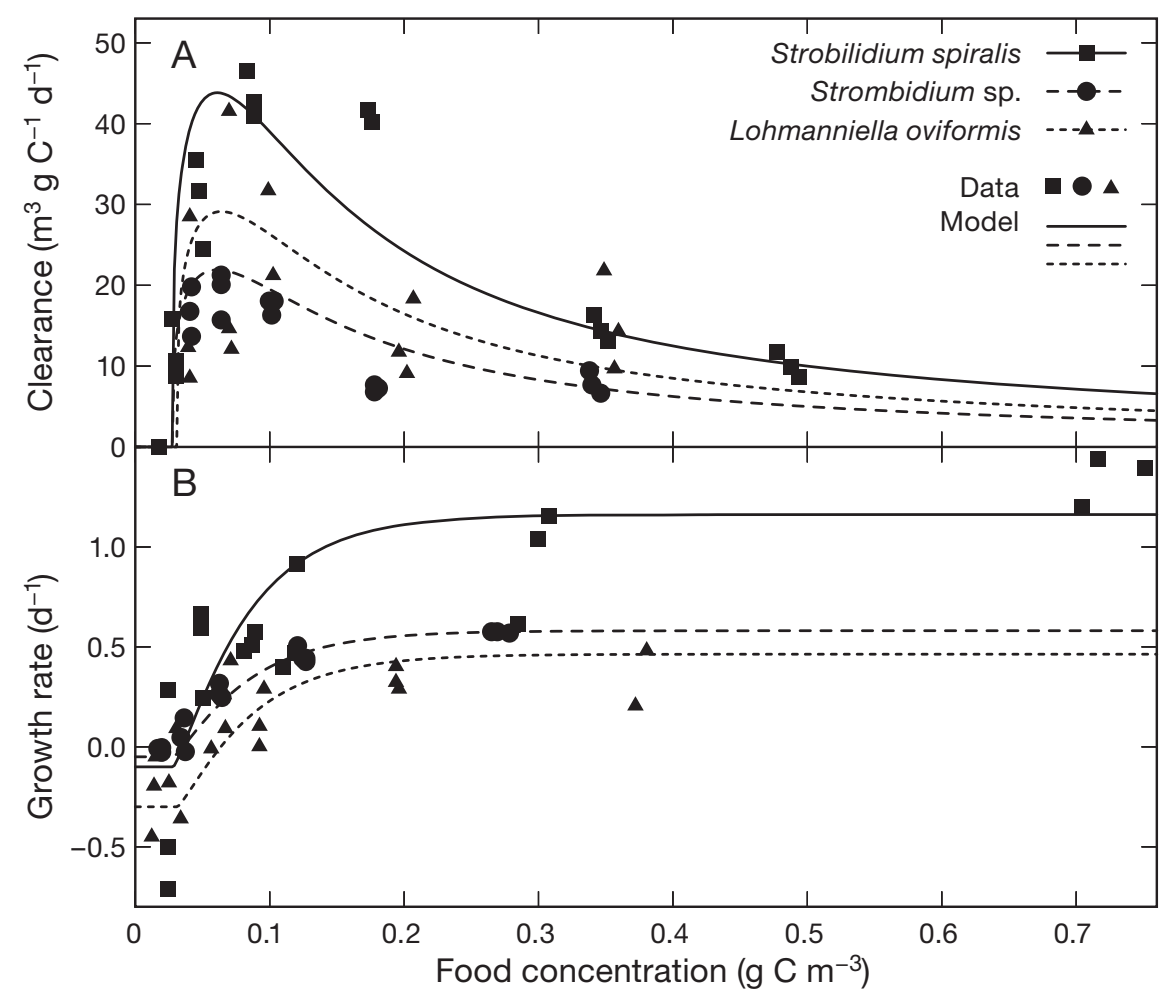

Fig. 6. Validation of the optimal current-feeding model with data of 3 planktonic ciliates grazing on (A) Nephroselmis pyriformis (Strombidium sp. and Lohmaniella oviformis) or (B) N. pyriformis and Hemiselmis sp. (Strobilidium spiralis). Data are from Gismervik (2005). Parameters are detailed in Table 2

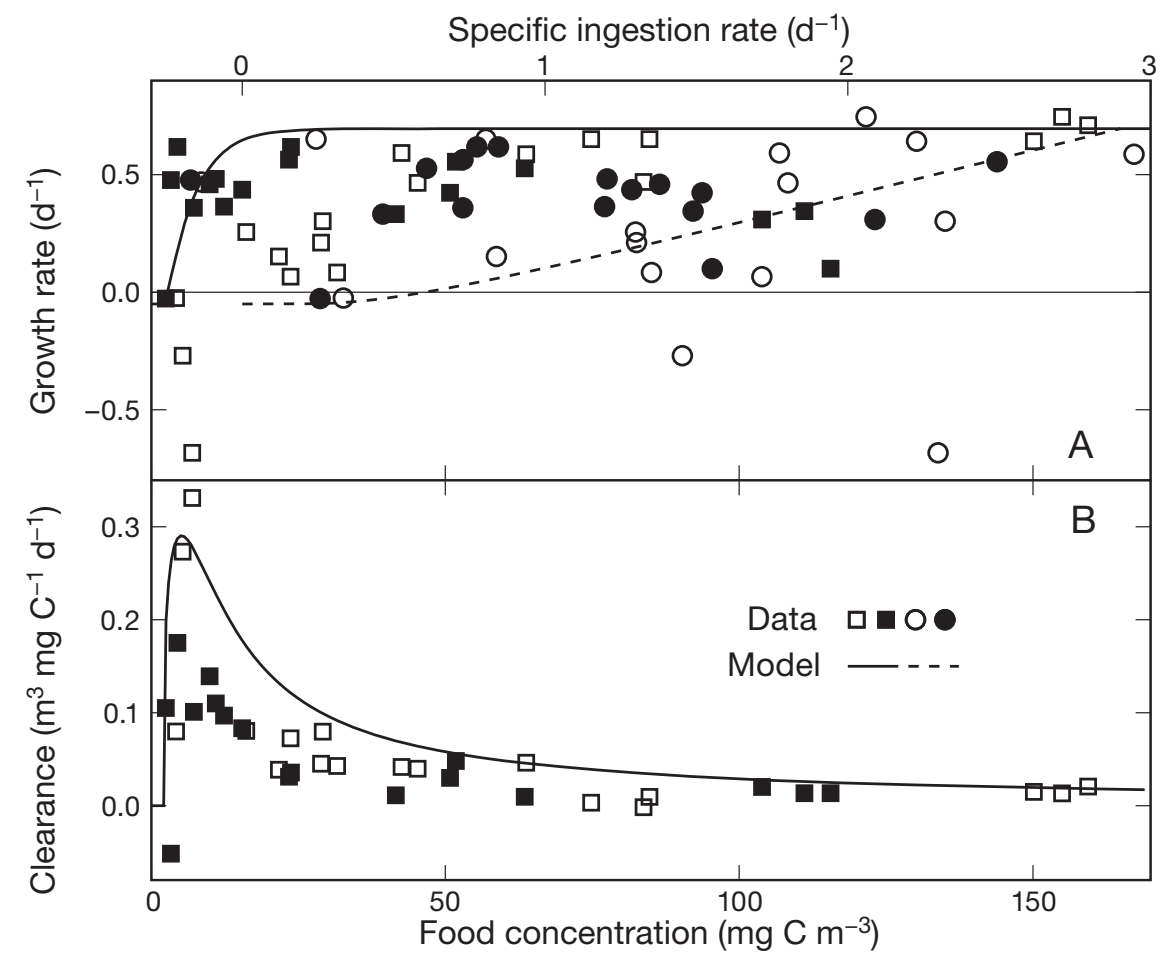

Fig. 7. Validation of the optimal current-feeding model with data of the heterotrophic dinoflagellate Gymnodinium sp. feeding on Isochrysis galbana in a 2 d experiment. Open symbols: Day 1; closed symbols: Day 2. Squares and solid lines indicate relationships with food concentration (bottom axis), circles and dashed line with specific ingestion rate (top axis). Data are from Strom (1991). Parameters are detailed in Table 2 


\section{DISCUSSION}

\section{Respiration}

The composition of respiration (shaded areas in Fig. 4B) draws a picture which differs qualitatively from those proposed earlier (e.g. Steele \& Mullin 1977, Vidal $1980 b)$, in which the cost of foraging is relatively small and decreases with increasing growth rate, and total respiration is dominated by specific dynamic action. The idea that the cost of foraging should decline with increasing growth rate is based on the observed reduction in clearance (Vidal 1980b), which in turn is based on the implicit assumption that clearance can be used as a proxy for foraging activity. However, our OCF model demonstrates that this is not necessarily the case (Fig. 4A,B), and predicts that the cost of foraging $\left(C_{\mathrm{f}} A_{\mathrm{f}}\right)$ increases with growth rate and also dominates total respiration energy loss except very close to the feeding threshold, whereas specific dynamic action (metabolic cost of assimilation, $C_{\mathrm{a}} E I$ ) becomes significant only at intermediate to high rates of net production (Fig. 4B).

The low energy requirement of a feeding current calculated from theoretical considerations has been used to suggest that the associated respiratory cost should be very low compared to total respiration (Fenchel 1980). However, these calculations only consider very crude estimates of the actually very low efficiency with which the feeding current is generated (Riisgård 2007). Svetlichny \& Hubareva (2005) interpreted observations of very low gross efficiencies of locomotion in copepods as indicating that energy dissipation in feeding currents contributes only negligibly to the overall energy requirement of a feeding current. Generating a feeding current comprises not only muscle activity in legs, feeding appendages, mouth parts, etc., but also increased activity of the animal's circulatory system needed for supplying energy and oxygen and collecting and removing waste products. While more research is needed to elicit the actual contributions of these processes to the total energy demand of foraging activity, it is nevertheless clear that a low energy requirement of the feeding current itself does not necessarily imply a low energetic cost of foraging, covering the energy demand of all required metabolic, circulatory, and muscle activity.

Another argument in favour of the large contribution of foraging to total respiratory costs can be derived from the observation that feeding thresholds have developed independently in several different organism groups, e.g. in copepods, ciliates, and apparently also dinoflagellates (Figs. 4 to 7 ). Although a feeding threshold might appear trivial at first, it requires a capacity to measure food concentration independently from the actual feeding process, since otherwise the organisms could not know when to start foraging again once feeding ceased. Thus, the development and conservation of such a complex feeding behaviour indicates that the possibility of down-regulating their feeding current must represent a strong advantage for these organisms, which is difficult to imagine if the cost of foraging was really insignificant. Only if the contribution of foraging activity to total respiration costs is large, as suggested by the OCF model (Fig. 4B), zooplankton could significantly extend their ability to survive prolonged periods without food by down-regulating foraging activity at low food concentration.

The assumed linear relationships between strength of feeding current $F$ and foraging activity $A_{\mathrm{f}}$ in Eq. (5) and between respiration $R$ and $A_{\mathrm{f}}$ in Eq. (2) imply a linear relation between feeding-current intensity and energy requirement of foraging, which contrasts with assumptions of quadratic or cubic relationships in previous optimal foraging models (Lam \& Frost 1976, Lehman 1976, Gerritsen \& Strickler 1977, Visser et al. 2009). The assumption of a quadratic relationship was based on the quadratic dependence of energy dissipation on velocity in laminar flow (Lehman 1976). However, copepods regulate the intensity of their feeding current by varying the fraction of time in which the feeding current is active rather than varying its velocity, implying a linear relationship with energy consumption (Price \& Paffenhöfer 1986). Similarly, a linear dependence of respiration on swimming speed in copepods was observed by Buskey (1998). Thus, linear energetic costs of both swimming and feeding-current generation could explain why the OCF model could describe the feeding behaviour of a (cruise feeding) dinoflagellate (Fig. 7). As noted by Price \& Paffenhöfer (1986), the assumption of a quadratic dependence could lead to overestimating energy requirements for high feedingcurrent intensities. More importantly with respect to feeding thresholds, however, an assumed quadratic relationship would severely underestimate energy requirements of very weak current-feeding activity, which is why none of the previous optimal foraging models predicted feeding thresholds. The OCF model predicts that a peak in clearance at a food concentration above zero is indicative of a feeding threshold. Minimal food concentrations applied in most laboratory studies are well above the feeding thresholds predicted by the OCF model. Hence, direct evidence for feeding thresholds, i.e. zero clearance at above-zero food concentration, is scarce but can be found (e.g. Durbin \& Durbin 1992, Gismervik 2005, Fig. 6A).

\section{Feeding thresholds}

The lack of clear evidence for feeding thresholds in microzooplankton has presented a problem for our 
understanding of the ecology of oligotrophic and high nutrient-low chlorophyll regions, as the zooplankton communities in these regions are thought to be dominated by microzooplankton (Strom et al. 2000, Paffenhöfer et al. 2007). As clarified by Strom et al. (2000), the relatively stable lower limit for chlorophyll (chl) concentrations in these regions appears to require a community grazing threshold. Such a grazing threshold of the whole zooplankton community has indeed been reported by Lessard \& Murrell (1998) for the Sargasso Sea, which is difficult to reconcile with the idea that small microzooplankton, which dominate the zooplankton community there, have no feeding threshold. Recently, Gismervik (2005) presented clear evidence for feeding thresholds in ciliates (Fig. 6). Data from an earlier study for the heterotrophic dinoflagellate Gymnodinium sp. feeding on Isochryis galbana (Strom 1991) revealed a clearance peak above the lowest food concentrations (Fig. 7B), indicating the presence of a feeding threshold. Strom (1991) also found that Gymnodinium sp. exhibited a feeding threshold for Synechococcus sp. when initial food concentration was low $\left(<20 \mu \mathrm{g} \mathrm{C} \mathrm{l}^{-1}\right)$, which was not observed when initial food concentration was higher. Such an apparently inconsistent behaviour with different initial conditions could point to insufficient acclimation of the organisms to the experimental setup. This is not unlikely, considering that it can take heterotrophic flagellates well in excess of $100 \mathrm{~h}$ to adapt to a change in food supply (Fenchel 1982), whereas the animals are typically allowed to acclimate to new experimental conditions for only 2 to 3 d (e.g. Strom 1991, Hansen 1992).

The relationship between $\phi$ and cell diameter of food algae (Table 2) implies an inverse relationship between prey size and feeding threshold (Eq. 14, Fig. 5 inset), although the lowest food concentrations applied by Frost (1972) were apparently still too high in order to observe the feeding thresholds directly. Such a relationship between food particle size and feeding threshold suggests that the frequently reported preference for larger food items (Frost 1972, Rollwagen Bollens \& Penry 2003) could actually be passively determined by the ability of the predator to detect these particles in its feeding current. Passive food preferences could justify the use of the concept of effective food concentration (Ambler 1986) manifest in Eq. (16), but probably only so long as the predator employs the same feeding mode for all kinds of prey involved (e.g. in Paffenhöfer 1984). At least some copepods can switch between current and ambush feeding (Kiørboe et al. 1996) and the mode of detection can also vary between chemoreception of phytoplankton (e.g. Gill \& Poulet 1988, Paffenhöfer \& Lewis 1990) and mechanoreception of large and motile prey (DeMott \& Watson 1991). Hence, more elaborate formulations will probably be required for accurate representation of omnivory involving phytoplankton and zooplankton as prey in plankton models.

The functional relationship between prey size and feeding threshold $P_{\text {th }}$ appears to be valid for both copepods and ciliates but not for dinoflagellates (Fig. 5 inset). Given the vast size range among ciliates and copepods (Table 2), a common prey size $-P_{\text {th }}$ relationship is a rather surprising finding, as it implies that the feeding threshold has very little to do with predatorprey size ratio. Although dinoflagellates are smaller than copepods and ciliates, the Gymnodinium sp. used in Strom (1991) reaches about half the size of Lohmanniella oviformis, whereas the sizes of the ciliates and copepods considered here span 5 orders of magnitude (Table 2). Thus it appears very unlikely that the difference in the prey size-dependence of $P_{\text {th }}$ between dinoflagellates, copepods and ciliates is due to the difference in predator size. This leaves only the difference in feeding behaviour, i.e. swimming as opposed to generating a feeding current, as an explanation for the different functional relationships of $P_{\text {th }}$ and prey size between dinoflagellates and the current feeders. Nevertheless, the feeding threshold of about $20 \mathrm{mg} \mathrm{C} \mathrm{m}^{-3}$, observed by Strom (1991) for Gymnodinium feeding on Synechococcus, is much larger than the threshold suggested by our model fit for feeding on Isochrysis galbana (Fig. 7), which is much larger than Synechococcus. Hence, inverse relationships between food particle size and feeding threshold, albeit different from the one for current feeders, could also apply to dinoflagellates and other microzooplankton groups with similar feeding behaviour.

\section{Cost of foraging}

Interestingly, the cost of foraging appears to be much lower in copepods than in ciliates and dinoflagellates, as is the case for the cost of assimilation (Table 2), yet the feeding thresholds of copepods are comparable to those of ciliates and dinoflagellates. This is due to the much larger value of $\phi$ (relating foraging effort to potential clearance) in the smaller organisms, resulting in much higher maximal clearance rates than are achieved by larger organisms. These high rates of clearance in small organisms have been interpreted as indicating efficient feeding at low food concentrations and, accordingly, lower food concentrations were used for predators with smaller body size (see Table 2 ) in the feeding experiments with copepods ( 0 to $1.7 \mathrm{~g} \mathrm{C} \mathrm{m}^{-3}$, Figs. 4 \& 5), ciliates ( 0 to $0.8 \mathrm{~g} \mathrm{C} \mathrm{m}^{-3}$, Fig. 6 ), and dinoflagellates (0 to $0.17 \mathrm{~g} \mathrm{C} \mathrm{m}^{-3}$, Fig. 7). Nevertheless, copepods reach about the same maximal growth rate of about $0.5 \mathrm{~d}^{-1}$ (Table 2) as the smaller organisms used in the present study, except Strobilidium spiralis 
(Fig. 6B), and they seem to be adapted to a similar range of food concentrations as ciliates and dinoflagellates. Owing to their lower costs of foraging and assimilation, however, copepods should be able to transfer biomass more efficiently from one trophic level to the next than microzooplankton.

\section{Assimilation efficiency}

The predicted relationship between food concentration and assimilation efficiency in the OCF model (Fig. 4D), when representing copepods in a plankton model, would cause an increase in remineralisation relative to export of faecal pellets at low food concentrations, such as are characteristic of oligotrophic systems. Steele (1998) suggested that microzooplankton, forming part of the microbial loop, are mostly responsible for nutrient remineralisation, whereas metazooplankton contribute to export production by releasing faecal pellets. Steele (1998) accordingly separated grazing between (implicit) microzooplankton and (explicit) metazooplankton in his implicit microbial loop (IML) formulation. This model is similar to OCF in that it effectively increases the assimilation efficiency of the zooplankton community at low food concentrations, although the underlying mechanism is very different: OCF theory predicts that changes in assimilation efficiency result from dynamic adjustments in feeding behaviour within species, whereas the IML model implies that assimilation efficiency varies due to strong shifts in community composition with static feeding behaviour of individual species. Steele (1998) implemented his IML in a nutrient-phytoplankton-zooplankton (NPZ) model simulating the spring bloom and subsequent transition to stratified summer conditions for the Bermuda Atlantic Time-series Study (BATS) site (Steele \& Henderson 1993, Steele 1998). The IML model produces much higher ammonium concentrations and much lower export ratios in a simulation for BATS, and is thus more realistic than a control simulation with fixed assimilation efficiency (Steele 1998).

\section{Plankton dynamics}

In order to analyse the effects of the novel features of the OCF model on plankton model behaviour, we have reproduced the simulations by Steele (1998) and implemented our OCF model in the same simple NPZ environment (Appendix 1). Fig. 8 compares the behaviour of the IML and OCF models for the BATS simulation described in Steele \& Henderson (1993) and Steele (1998). The high ammonium concentrations and low export ratios predicted by the IML model are connected to strong changes in zooplankton community composition, reflected in the ratio of total grazing to copepod grazing $G_{\mathrm{N}}^{-1}$ (Fig. 8A,B), which is the mechanism behind the variations in effective assimilation efficiency in the IML model. The OCF parameters were tuned to obtain an approximate match of the behaviour of the IML model without modifying any of the parameters defining primary production and predation on metazooplankton by higher trophic levels (Table 3). The parameter settings are supposed to represent a zooplankton community and are thus not directly comparable to those in Table 2, which are for individual species. Nevertheless, the parameter estimates are most similar to those for ciliates in Table 2. Overall, the OCF model behaves much more similarly to the IML than to the control simulation shown in Steele (1998), both in terms of phytoplankton and nutrient dynamics and, most importantly, also export ratios (Fig. 8A,C), although the OCF model has more pronounced oscillations and somewhat higher export

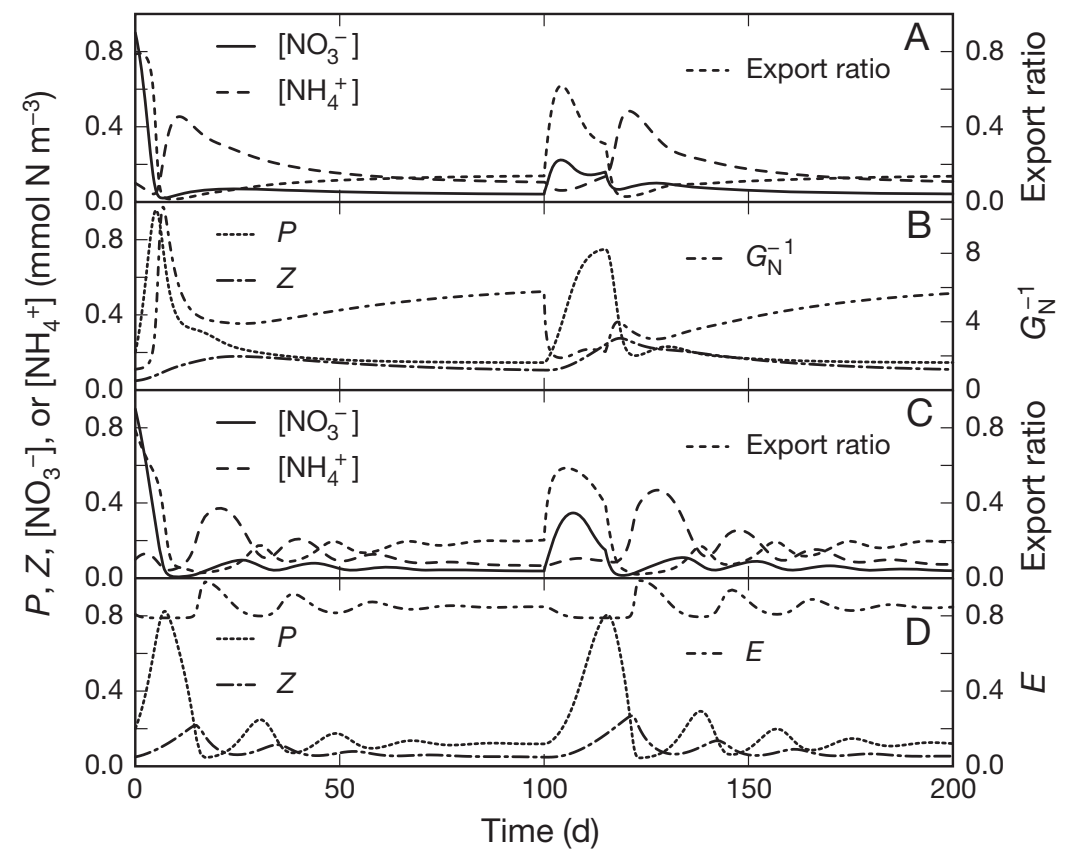

Fig. 8. (A,B) Simulations with the implicit microbial loop model (see Appendix 1) presented by Steele (1998). (C,D) Simulations with the implicit microbial loop model with copepods replaced by an optimal current feeder. $P$ and $Z$ are phytoplankton and zooplankton concentration, respectively, $G_{\mathrm{N}}^{-1}$ is the ratio of total grazing to copepod grazing, export ratio is the ratio of export to total primary production, and $E$ is assimilation efficiency. Parameter settings are listed in Table 3 
Table 3. Parameter settings used for microbial loop model (Fig. 8, Appendix 1). $\mathrm{N}$ : nitrogen

\begin{tabular}{|c|c|c|c|}
\hline Parameter & Setting & Units & Description \\
\hline$A_{1}$ & 2 & & Phytoplankton preference for $\mathrm{NH}_{4}^{+}$ \\
\hline$A_{4}$ & 0.04 & & Light attenuation coefficient for water \\
\hline$A_{5}$ & 0.03 & $\mathrm{~m}^{3} \mathrm{mmol} \mathrm{N}^{-1}$ & $\begin{array}{l}\text { Light attenuation coefficient for phyto- } \\
\text { plankton }\end{array}$ \\
\hline$A_{6}$ & 0.05 & $d^{-1}$ & Phytoplankton respiration rate \\
\hline$A_{\mathrm{k}}$ & 0.005 & $d^{-1}$ & Mixing rate at the base of the mixed layer \\
\hline$B_{1}$ & 0.5 & $\mathrm{~d}^{-1}$ & Maximum grazing rate \\
\hline$B_{2}$ & 0.3 & $\mathrm{mmol} \mathrm{N} \mathrm{m}^{-3}$ & Half saturation concentration for grazing \\
\hline$C_{2}$ & 0.3 & & Assimilation efficiency \\
\hline$D_{3}$ & 0.3 & $\mathrm{~m}^{3} \mathrm{mmol} \mathrm{N}^{-1} \mathrm{~d}^{-1}$ & Higher predation on zooplankton \\
\hline$f_{\mathrm{r}}$ & 0.3 & & Recycled fraction of higher predation \\
\hline$f_{\mathrm{x}}$ & 0.3 & & Excreted fraction (export to deep water) \\
\hline$K_{\mathrm{N}}$ & 0.2 & $\mathrm{mmol} \mathrm{N} \mathrm{m}{ }^{-3}$ & $\begin{array}{l}\text { Half saturation concentration for phyto- } \\
\text { plankton }\end{array}$ \\
\hline$N_{0}$ & $2^{\mathrm{a}}$ & $\mathrm{mmol} \mathrm{N} \mathrm{m}^{-3}$ & $\mathrm{NO}_{3}^{-}$concentration below mixed layer \\
\hline$\psi$ & 21 & $\mathrm{~m}^{3} \mathrm{mmol} \mathrm{N}^{-1} \mathrm{~d}^{-1}$ & $\mathrm{NH}_{4}^{+}$inhibition of $\mathrm{NO}_{3}^{-}$uptake \\
\hline$V_{\max }$ & 0.04 & $\mathrm{~d}^{-1}$ & Maximum phytoplankton growth rate \\
\hline$V_{\mathrm{s}}$ & 0.03 & $d^{-1}$ & Sinking loss rate out of the mixed layer \\
\hline$\beta$ & 0.2 & & Assimilation coefficient \\
\hline$C_{\mathrm{a}}$ & 0.3 & & Cost of assimilation coefficient \\
\hline$C_{\mathrm{f}}^{*}$ & 0.3 & & Effective cost of foraging coefficient \\
\hline$E_{\max }$ & 0.99 & & Maximum assimilation efficiency \\
\hline$I_{\max }$ & 1.2 & $\mathrm{~d}^{-1}$ & Maximum specific ingestion rate \\
\hline$\phi$ & 13 & $\mathrm{~m}^{3} \mathrm{mmol} \mathrm{N} \mathrm{N}^{-1}$ & Prey capture coefficient \\
\hline$R_{\mathrm{M}}$ & 0.16 & $\mathrm{~d}^{-1}$ & Specific maintenance respiration \\
\hline
\end{tabular}

for classifying zooplankton into functional groups in multiple functionaltype models.

Assimilation efficiency declines as a predator allocates more of its energy to foraging and increases as more energy is allocated for assimilation. Growth is maximised in the OCF model by allocating less energy to foraging and more towards assimilation as food becomes scarce. The consequent increase in assimilation efficiency increases respiration (remineralisation) at the expense of excretion (export). Thus optimal current feeding could explain at least to a large part the differences between recycling and export production; therefore the required changes in community composition between subsequent seasonal regimes could be less extreme than previously thought.

Acknowedgements. We thank J. H. Steele for prompt help with the reconstruction of the IML simulations. We are very grateful to A. Oschlies, G.-A. Paffenhöfer, and 2 anonymous reviewers for helpful comments and discussions on the manuscript.

\section{LITERATURE CITED}

ratios than the IML model. Export ratio variations are linked to variations in assimilation efficiency in both the OCF and IML (not shown) models. However, since assimilation efficiency responds to adjustments in feeding behaviour within the existing zooplankton community in the OCF model (Fig. 8D), much smaller shifts in community composition would be required to explain the difference in export ratio between bloom and non-bloom conditions.

The main advantage of the OCF model over previous formulations lies in its inherent links among ingestion, respiration, assimilation efficiency, and feeding threshold. Feeding thresholds appear to be a general requirement for stability in plankton systems (Strom et al. 2000). Lessard \& Murrell (1998) found a feeding threshold for the zooplankton community at BATS of about $0.035 \mathrm{mg} \mathrm{chl} \mathrm{m}^{-3}$, which would correspond to the lowest feeding threshold in Table 2 if the C:chl ratio was about 60 . Feeding thresholds seem to follow a similar relationship with prey size for ciliates and copepods, with much lower feeding thresholds in dinoflagellates probably due to their different feeding behaviour. In addition, most parameter estimates in Table 2 are much more similar within than among systematic groups. Therefore, we suggest that phylogenetic grouping is more appropriate than predator size
Ambler JW (1986) Formulation of an ingestion function for a population of Paracalanus feeding on mixtures of phytoplankton. J Plankton Res 8:957-972

Barry DA, Parlange JY, Li L, Prommer H, Cunningham CJ, Stagnitti F (2000) Analytical approximations for real values of the Lambert W-function. Math Comput Simul 53: 95-103

Baumert H (1996) On the theory of photosynthesis and growth in phytoplankton. Part I: light limitation and constant temperature. Int Rev Gesamten Hydrobiol 81: 109-139

Buskey EJ (1998) Energetic costs of swarming behavior for the copepod Dioithona oculata. Mar Biol 130:425-431

Conover RJ (1968) Zooplankton-life in a nutritionally dilute environment. Am Zool 8:107-118

DeMott WR, Watson MD (1991) Remote detection of algae by copepods: responses to algal size, odors and motility. J Plankton Res 13:1203-1222

Durbin EG, Durbin AG (1992) Effects of temperature and food abundance on grazing and short-term weight change in the marine copepod Acartia hudsonica. Limnol Oceanogr 37:361-378

Fenchel T (1980) Relation between particle size selection and clearance in suspension-feeding ciliates. Limnol Oceanogr

> Fenchel T (1982) Ecology of heterotrophic microflagellates. III. Adaptations to heterogeneous environments. Mar Ecol Prog Ser 9:25-33

Frost BW (1972) Effects of size and concentration of food 25:733-738 
particles on the feeding behavior of the marine planktonic copepod Calanus pacificus. Limnol Oceanogr 17: 805-815

Frost BW (1975) A threshold feeding behavior in Calanus pacificus. Limnol Oceanogr 20:263-266

Fujii K, Holling CS, Mace PM (1986) A simple generalized model of attack by predators and parasites. Ecol Res 1: 141-156

Garcia R, Moss F, Nihongi A, Strickler JR and others (2007) Optimal foraging by zooplankton within patches: the case of Daphnia. Math Biosci 207:165-188

> Gentleman W, Leising A, Frost B, Strom S, Murray J (2003) Functional responses for zooplankton feeding on multiple resources: a review of assumptions and biological dynamics. Deep-Sea Res II 50:2847-2875

Gerritsen J, Strickler JR (1977) Encounter probabilities and community structure in zooplankton: a mathematical model. J Fish Res Board Can 34:73-82

Gerritsen J, Porter KG, Strickler JR (1988) Not by sieving alone: observations of suspension feeding in Daphnia. Bull Mar Sci 43:366-376

Gill CW, Poulet SA (1988) Responses of copepods to dissolved free amino acids. Mar Ecol Prog Ser 43:269-276

Gismervik I (2005) Numerical and functional responses of choreo- and oligotrich planktonic ciliates. Aquat Microb Ecol 40:163-173

Hansen PJ (1992) Prey size selection, feeding rates and growth dynamics of heterotrophic dinoflagellates with special emphasis on Gyrodinium spirale. Mar Biol 114: $327-334$

> Hassett RP, Landry MR (1983) Effects of food-level acclimation on digestive enzyme activities and feeding behavior of Calanus pacificus. Mar Biol 75:47-55

Holling CS (1959) Some characteristics of simple types of predation and parasitism. Can Entomol 91:385-398

Holling CS (1973) Resilience and stability of ecological systems. Annu Rev Ecol Syst 4:1-23

Ivlev VS (1961) Experimental ecology of the feeding of fishes. Yale University Press, New Haven, CT, p 19-40

Jonsson PR, Tiselius P (1990) Feeding behaviour, prey detection and capture efficiency of the copepod Acartia tonsa feeding on planktonic ciliates. Mar Ecol Prog Ser 60:35-44

Jørgensen CB (1983) Fluid mechanical aspects of suspension feeding. Mar Ecol Prog Ser 11:89-103

Kiørboe T, Møhlenberg F, Nicolajsen H (1982) Ingestion rate and gut clearance in the planktonic copepod Centropages hamatus (Lilleborg) in relation to food concentration and temperature. Ophelia 21:181-194

Kiørboe T, Møhlenberg F, Hamburger K (1985) Bioenergetics of the planktonic copepod Acartia tonsa: relation between feeding, egg production and respiration, and composition of specific dynamic action. Mar Ecol Prog Ser 26:85-97

Kiørboe T, Saiz E, Viitasalo M (1996) Prey switching behaviour in the planktonic copepod Acartia tonsa. Mar Ecol Prog Ser 143:65-75

Koehl MAR, Strickler JR (1981) Copepod feeding currents: food capture at low Reynolds number. Limnol Oceanogr 26:1062-1073

Lam RK, Frost BW (1976) Model of copepod filtering response to changes in size and concentration of food. Limnol Oceanogr 21:490-500

Landry MR, Hassett RP, Fagerness V, Downs J, Lorenzen CJ (1984) Effect of food acclimation on assimilation efficiency of Calanus pacificus. Limnol Oceanogr 29:361-364

Lehman JT (1976) The filter-feeder as an optimal forager, and the predicted shapes of feeding curves. Limnol Oceanogr 21:501-516
Lessard EJ, Murrell MC (1998) Microzooplankton herbivory and phytoplankton growth in the northwestern Sargasso Sea. Aquat Microb Ecol 16:173-188

Paffenhöfer GA (1984) Food ingestion by the marine planktonic copepod Paracalanus in relation to abundance and size distribution of food. Mar Biol 80:323-333

> Paffenhöfer GA, Lewis KD (1990) Perceptive performance and feeding behavior of calanoid copepods. J Plankton Res 12:933-946

Paffenhöfer GA, Sherr BF, Sherr EB (2007) From small scales to the big picture: persistence mechanisms of planktonic grazers in the oligotrophic ocean. PSZN I: Mar Ecol 28: 243-253

Parsons TR, LeBrasseur RJ, Fulton JD (1967) Some observations on the dependence of zooplankton grazing on the size and concentration of phytoplankton blooms. J Oceanogr Soc Jpn 23:10-17

> Price HJ, Paffenhöfer GA (1986) Effects of concentration on the feeding of a marine copepod in algal monocultures and mixtures. J Plankton Res 8:119-128

- Pyke GH (1984) Optimal foraging theory: a critical review. Annu Rev Ecol Syst 15:523-575

> Riisgård HU (2007) Biomechanics and energy cost of the amphipod Corophium volutator filter-pump. Biol Bull 212: $104-114$

Rollwagen Bollens GC, Penry DL (2003) Feeding dynamics of Acartia spp. copepods in a large, temperate estuary (San Francisco Bay, CA). Mar Ecol Prog Ser 257:139-158

> Steele JH (1998) Incorporating the microbial loop in a simple plankton model. Proc Biol Sci 265:1771-1777

Steele JH, Henderson EW (1992) The role of predation in plankton models. J Plankton Res 14:157-172

Steele JH, Henderson EW (1993) The significance of interannual variability. In: Evans GT, Fasham MJR (eds) Towards a model of ocean biogeochemical processes. SpringerVerlag, Berlin, NATO ASI Series, Vol. 10, p 237-260

Steele JH, Mullin MM (1977) Zooplankton dynamics. In: Goldberg ED, McCave IN, O'Brien JJ, Steele JH (eds) Marine modeling. Wiley, New York, p 857-890

Stoecker DK (1984) Particle production by planktonic ciliates. Limnol Oceanogr 29:930-940

Strom SL (1991) Growth and grazing rates of the herbivorous dinoflagellate Gymnodinium sp. from the open subarctic Pacific Ocean. Mar Ecol Prog Ser 78:103-113

Strom SL, Miller CB, Frost BW (2000) What sets lower limits to phytoplankton stocks in high-nitrate, low-chlorophyll regions of the open ocean? Mar Ecol Prog Ser 193: 19-31

> Svetlichny LS, Hubareva ES (2005) The energetics of Calanus euxinus: locomotion, filtration of food and specific dynamic action. J Plankton Res 27:671-682

Vidal J (1980a) Physioecology of zooplankton. I. Effects of phytoplankton concentration, temperature, and body size on the growth rate of Calanus pacificus and Pseudocalanus sp. Mar Biol 56:111-134

- Vidal J (1980b) Physioecology of zooplankton. III. Effects of phytoplankton concentration, temperature, and body size on the metabolic rate of Calanus pacificus. Mar Biol 56: 195-202

Visser AW, Stips A (2002) Turbulence and zooplankton production: insights from PROVESS. J Sea Res 47:317-329

> Visser AW, Mariani P, Pigolotti S (2009) Swimming in turbulence: zooplankton fitness in terms of foraging efficiency and predation risk. J Plankton Res 31:121-133

Wlodarczyk E, Durbin AG, Durbin EG (1992) Effect of temperature on lower feeding thresholds, gut evacuation rate, and diel feeding behavior in the copepod Acartia hudsonica. Mar Ecol Prog Ser 85:93-106 
Appendix 1. Equations to reconstruct Steele's microbial loop formulation (see Fig. 8, Table 3)

We used the following equations to reconstruct Steele's (1998) implicit microbial loop formulation and compare its behaviour with that of the optimal current-feeding (OCF) model (modified from Steele \& Henderson 1993, Steele 1998):

$$
\begin{gathered}
\frac{\mathrm{d}\left[\mathrm{NO}_{3}^{-}\right]}{\mathrm{d} t}=-\frac{\mathrm{e}^{-\psi\left[\mathrm{NH}_{4}^{+}\right]}\left[\mathrm{NO}_{3}^{-}\right] F_{1}}{V_{\mathrm{N}}}+A_{\mathrm{k}}\left(N_{0}-\left[\mathrm{NO}_{3}^{-}\right]\right) \\
\frac{\mathrm{d}\left[\mathrm{NH}_{4}^{+}\right]}{\mathrm{d} t}=-\frac{A_{1}\left[\mathrm{NH}_{4}^{+}\right] F_{1}}{V_{\mathrm{N}}}+A_{6} P+r_{\mathrm{NH}_{4}^{+}} Z+D_{3} f_{\mathrm{r}} Z^{2} \\
\frac{\mathrm{d} P}{\mathrm{~d} t}=V_{\mathrm{N}}-A_{6} P-I Z-\left(V_{\mathrm{s}}+A_{\mathrm{k}}\right) P \\
\frac{\mathrm{d} Z}{\mathrm{~d} t}=(E I-R) Z-D_{3} Z^{2}
\end{gathered}
$$

where $\left[\mathrm{NO}_{3}{ }^{-}\right],\left[\mathrm{NH}_{4}{ }^{+}\right], P$, and $Z$ are nitrate, ammonium, phytoplankton, and zooplankton concentrations, respectively, in mmol $\mathrm{N} \mathrm{m}^{-3}, V_{\mathrm{N}}$ is nitrogen uptake (phytoplankton gross growth rate), defined as:

$$
V_{\mathrm{N}}=\left(\mathrm{e}^{-\psi\left[\mathrm{NH}_{4}^{+}\right]}\left[\mathrm{NO}_{3}^{-}\right]+A_{1}\left[\mathrm{NH}_{4}^{+}\right]\right) F_{1}, \quad F_{1}=\frac{V_{\max } P}{\left(K_{\mathrm{N}}+\left[\mathrm{NO}_{3}^{-}\right]+A_{1}\left[\mathrm{NH}_{4}^{+}\right]\right)\left(A_{4}+A_{5} P\right)}
$$

$r_{\mathrm{NH}_{4}^{+}}$is ammonium remineralisation, $N_{0}$ is nitrate concentration at the base of the mixed layer, and $A_{\mathrm{k}}$ and $V_{\mathrm{s}}$ are the phytoplankton sinking and vertical mixing coefficients (see Table 3 for a summary of the remaining parameters). The implicit microbial loop of Steele (1998) is obtained by substituting E, $I, R$, and $r_{\mathrm{NH}_{4}}$ with:

$$
\begin{gathered}
E=C_{2} G_{\mathrm{N}}, \quad I=G_{\mathrm{N}}^{-1} F_{2}, \quad R=0 \\
r_{\mathrm{NH}_{4}^{+}}=\left(G_{\mathrm{N}}^{-1}-f_{\mathrm{x}}-C_{2}\right) F_{2}, \quad G_{\mathrm{N}}^{-1}=1+\frac{K_{\mathrm{N}}}{\mathrm{NO}_{3}^{-}}, \quad F_{2}=B_{1} \frac{P^{2}}{B_{2}^{2}+P^{2}}
\end{gathered}
$$

where $G_{\mathrm{N}}^{-1}$ is the ratio of total grazing to copepod grazing and $F_{2}$ is copepod grazing, and the OCF model is implemented with the definitions for $E, I$, and $R$ from Eqs. (7) \& (8) and:

$$
r_{\mathrm{NH}_{4}^{+}}=R
$$

Editorial responsibility: Matthias Seaman, Oldendorf/Luhe, Germany
Submitted: August 12, 2009; Accepted: December 21, 2009 Proofs received from author(s): March 8, 2010 